\title{
Intrathecal Midazolam Added to Bupivacaine Prolongs the Duration of Spinal Blockade to T10 Dermatome in Orthopedic Patients
}

\author{
Department of Anaesthesiology and Pain Medicine, Seoul National University Bundang Hospital, Seongnam, \\ ${ }^{*}$ Chungnam National University Hospital, Daejeon, ${ }^{\dagger}$ Dongguk University Ilsan Hospital, Goyang, Korea
}

Mi Ja Yun, M.D., Yoon Hee Kim, M.D.*, Jin Hee Kim, M.D., Kyoung Ok Kim, M.D. , Aa Young Oh, M.D., and Hee Pyoung Park, M.D.

Background: Although the intrathecal (IT) administration of midazolam has been reported to have analgesic effect in humans, it is not clear whether IT midazolam can prolong the duration of sensory block to T10 dermatome that is required block level for lower extremity surgery. The effect of 1 or $2 \mathrm{mg}$ of IT midazolam added to bupivacaine on the duration of spinal anesthesia to T10 were examined in orthopedic patients.

Methods: Sixty six adult patients were randomly allocated to receive $11 \mathrm{mg}$ of intrathecal $0.5 \%$ hyperbaric bupivacaine alone (Group B, $\mathrm{n}=22$ ) or with $1 \mathrm{mg}$ (Group BM-1, $\mathrm{n}=22$ ) or $2 \mathrm{mg}$ (Group BM-2, $\mathrm{n}=22$ ) of midazolam. Both the patients and the observers were blinded to the drug solutions and patient groups. The onset and duration of sensory block to T10, BIS, OAA/S scale, hemodynamic variables, and side effects during the operation and recovery were compared among the groups.

Results: The onset of sensory and motor block were not different among the groups. However, the duration of sensory block to T10 in the Group BM-2 was prolonged more 52.2, 42.2 minutes than the Group B and the Group BM-1, respectively. The BIS scale of the Group BM-2 tended to be lower than the Group B and the Group BM-1 but there were no statistical significance. The OAA/S scale were significantly higher in the Group BM-2 than the Group B and the Group BM-1 during operation. There were no differences in hemodynamic variables and side effects among the groups.

Conclusions: Intrathecal addition of midazolam $2 \mathrm{mg}$ to bupivacaine prolonged the duration of spinal block to T10 in orthopedic patients. (Korean J Anesthesiol 2007; 53: S 22 8)

Key Words: intrathecal midazolam, sedation, sensory, spinal anesthesia.

\section{INTRODUCTION}

Unexpected early regression of spinal block or prolonged operation can cause intraoperative pain. Increasing the dose of local anesthetics, addition of opioids or clonidine to local anesthetics for spinal anesthesia would be helpful for prolonging the spinal blockade but may cause hemodynamic instability, nausea, urinary retention, respiratory depression ${ }^{1)}$ and delayed recovery from motor block. $^{2)}$ IT administration of

Received : December 19, 2006

Corresponding to : Yoon Hee Kim, Department of Anaesthesiology and Pain Medicine, Chungnam National University Hospital, Daesa-dong, Jung-gu, Daejeon 301-721, Korea. Tel: 82-42-280-7840, Fax: 042280-7968, E-mail: yhkim0404@cnu.ac.kr midazolam has been reported to have analgesic effect in animals $^{3-5)}$ and humans without significant side effects. ${ }^{6-8)}$ Some studies demonstrated that IT midazolam prolonged the duration of sensory block to perineal area. ${ }^{9-11)}$ However, they are not important informations for the lower extremity surgery with a tourniquet and it is not clear whether IT midazolam can prolong the duration of sensory block to T10 dermatome that is required block level for lower extremity surgery. The sedative effect of IT midazolam is controversial. In addition to analgesic effect, simultaneous sedative effect of $2 \mathrm{mg}$ of IT midazolam was reported. $^{10,12)}$ However, significant sedative effect of 1 or $2 \mathrm{mg}$ of IT midazolam was not found in other study. ${ }^{9,13,14)}$

Therefore this study was performed to evaluate the analgesic effect and sedative effect of IT midazolam for spinal anesthesia in orthopedic patients. 
Table 1. Demographic and Anesthesia Data

\begin{tabular}{lccc}
\hline \multicolumn{1}{c}{ Variables } & $\begin{array}{c}\text { Group B } \\
(\mathrm{n}=20)\end{array}$ & $\begin{array}{c}\text { Group BM-1 } \\
(\mathrm{n}=21)\end{array}$ & $\begin{array}{c}\text { Group BM-2 } \\
(\mathrm{n}=19)\end{array}$ \\
\hline Age (y) & $62.6 \pm 12.6$ & $63.3 \pm 9.4$ & $59.5 \pm 14.5$ \\
Gender (M/F) & $5 / 15$ & $2 / 19$ & $5 / 14$ \\
Weight (kg) & $59.5 \pm 9.3$ & $63.8 \pm 11.3$ & $68.5 \pm 25.3$ \\
Height (cm) & $153.5 \pm 9.4$ & $153.6 \pm 5.7$ & $155.1 \pm 20.8$ \\
ASA status (1/2) & $5 / 15$ & $7 / 14$ & $5 / 14$ \\
Surgical indications & & & 6 \\
$\quad$ Total hip replacement & 14 & 6 & 13 \\
$\quad$ Femur fracture & $114.3 \pm 30.8$ & $113.0 \pm 15.8$ & $115.0 \pm 29.1$ \\
Duration of surgery (minute) & $874.8 \pm 288.9$ & $1,024.2 \pm 363.4$ & $957.8 \pm 316.3$ \\
Crystalloid (ml) & $81.5 \pm 186.4$ & $38.8 \pm 119.5$ & $205.5 \pm 246.0$ \\
Colloid (ml) & $7.0 \pm 7.3$ & $9.7 \pm 10.1$ & $8.9 \pm 10.7$ \\
Ephedrine (mg) &
\end{tabular}

Values are in mean $\pm \mathrm{SD}$, number of patients. Group B: $0.5 \%$ hyperbaric bupivacaine $+0.4 \mathrm{ml}$ of $0.9 \%$ saline, Group BM-1: bupivacaine + midazolam $1 \mathrm{mg}$ in $0.2 \mathrm{ml}+0.2 \mathrm{ml}$ of $0.9 \%$ saline, Group BM-2: bupivacaine + midazolam $2 \mathrm{mg}$ in $0.4 \mathrm{ml}$.

\section{MATERIALS AND METHODS}

After protocol approval by the institutional review board and patient informed consent, 66 patients (ASA physical status 1 or 2) scheduled for lower extremity surgery under spinal anesthesia from January to June, 2006 were studied. Exclusion criteria were benzodiazepine medication history, alcohol or other substance abuse, and hepatic, renal, circulatory, respiratory, and psychiatric disorders. The demographic data were presented in Table 1.

All patients were premedicated with $1 \mathrm{mg}$ of intravenous midazolam (Midazolam inj ${ }^{\circledR}$, Bukwang pharmaceutical. Co. Ltd., Korea). The patients were randomly allocated to one of the three spinal anesthesia groups with a random allocation sequence generated by one of the authors (http://www. randomizer.org/form.htm). One of the authors who was not involved in patient care assigned participants to their groups.

The Group B $(\mathrm{n}=22)$ received $11 \mathrm{mg}$ of $0.5 \%$ hyperbaric bupivacaine (Marcaine Spinal heavy $0.5 \%, 5 \mathrm{mg} / \mathrm{ml}$, AstraZeneca, Sodertalje, Sweden) plus $0.4 \mathrm{ml}$ of $0.9 \%$ saline intrathecally. The group BM-1 $(\mathrm{n}=22)$ received $11 \mathrm{mg}$ of $0.5 \%$ hyperbaric bupivacaine plus $1 \mathrm{mg}$ of preservative-free midazolam in $0.2 \mathrm{ml}(5 \mathrm{mg} / \mathrm{ml})$ plus $0.2 \mathrm{ml}$ of $0.9 \%$ saline intrathecally. The group BM-2 $(\mathrm{n}=22)$ received $11 \mathrm{mg}$ of $0.5 \%$ hyperbaric bupivacaine plus $2 \mathrm{mg}$ of midazolam in 0.4 $\mathrm{ml}(5 \mathrm{mg} / \mathrm{ml})$ intrathecally.
Both the patients and the observers were blinded to the drug solutions and patient groups. The study solution was prepared by an anesthesiology nurse who was not involved in the administration of spinal anesthesia. The random allocation sequence was concealed until interventions were assigned. After $6 \mathrm{ml} / \mathrm{kg}$ of intravenous balanced salt solution, spinal anesthesia was performed with the patient in the lateral decubitus position using a 26-gauge Quincke spinal needle at the L3-L4 interspace. The study solution was injected through the spinal needle over 2 minutes in all groups. Electrocardiogram and arterial oxygen saturation, noninvasive blood pressure, heart rate, observer's assessment of alertness/sedation (OAA/S) scale $^{15)}$ were recorded every 5 minutes during the operation and then every 15 minutes for $1 \mathrm{~h}$ at postanesthetic recovery room. Intravenous crystalloids and if necessary, $5 \mathrm{mg}$ of ephedrine were given to maintain mean arterial blood pressure within $30 \%$ of baseline.

The onset of sensory and motor block were assessed at 5, 10, 15 minutes after spinal anesthesia and then every 15 minutes during operation and until $1 \mathrm{~h}$ of recovery period by pin-prick testing bilaterally along the midclavicular line using a 26-gauge hypodermic needle. The umbilicus level was considered as T10 dermatome and the duration of sensory block to T10 after spinal anesthesia was recorded. Motor block was assessed using a 6-point modified Bromage scale (MBS) (1 = complete motor block; 2 = almost complete block, the patient is able to move feet only; 3 = partial motor block, the patient 
is able to move the knees; $4=$ detectable weakness of hip flexion, the patient is able to raise the leg but is unable to keep it raised; $5=$ no detectable weakness of hip flexion; $6=$ no weakness at all). ${ }^{16)}$ The BIS monitoring was started from 30 minutes after the spinal anesthesia. Average BIS of 5 minutes duration was recorded until 120 minutes after the spinal anesthesia. All the patients received supplemental oxygen (5 L/minute) via facial mask. Operation time, infused volume of balanced salt solution and colloid, doses of ephedrine and side effects such as hypotension (systolic blood pressure < $70 \%$ of baseline), bradycardia (heart rate $<50$ beats $/ \mathrm{min}$ ), nausea, vomiting, oversedation (OAA/S 4 or 5), dizziness, airway obstruction and hypoxia $\left(\mathrm{SpO}_{2}<95 \%\right)$ were recorded. If the patients complain pain during operation, each dose of fentanyl (50 ug) were injected until the pain decrease enough to continue the operation.

Adverse effects, amnesia for the operation, pain (4 scale, 1 $=$ no pain, $2=$ mild pain, $3=$ moderate pain, $4=$ severe pain) were evaluated during recovery period. If the patients complained pain more than mild degree, the patients were informed to push the button of IV PCA (intravenous patient controlled analgesia, Auto $\operatorname{Med}^{\circledR}$ 3200, Ace-medical Co., Korea) with hydromorphone (bolus dose of $0.15 \mathrm{mg} / \mathrm{ml}$, with lockout interval 10 minutes) ${ }^{17)}$ until the pain decrease less than mild degree. The patient's satisfaction with their total perioperative experience was assessed with an 11-point numerical scale ( 0 , not at all satisfied and 10 , fully satisfied). Study participants were followed for 2 weeks for any neurologic deficits.

The sample size was determined based on a pilot study that suggested a sample size of 17 patients for each group to detect a 43.8 minutes difference in the duration of sensory block between the Group B and the Group BM-2 assuming a 45.1 minutes standard deviation within each group with a power of 0.8 (alpha $=0.05$ ).

One-way analysis of variance (ANOVA) was used for normally distributed parametric data. Nonparametric data were analyzed using the Kruskall-Wallis test. Repeated variables were analyzed with Repeated measure of one-way ANOVA. Post hoc multiple comparison test was done using the Bonferroni method. Statistical analysis were preformed with statistical software (Statistical Package for Social Science [SPSS] version 12.0 for Windows, SPSS, Inc.). A P value < 0.05 was considered statistically significant.

\section{RESULTS}

Two patients in Group B were excluded from the study due to failure to stick to protocol. One patient in Group BM-1 and 3 patients in Group BM-2 refused to attend the study and were excluded. Twenty, twenty-one and nineteen patients in Group B, BM-1, BM-2, respectively, were included in statistical analysis of this study.

Five, two, five patients in the Group B, BM-1, BM-2, did not have T10 sensory block at 15 minutes after the spinal block. All of the patients showed above T10 sensory block at 30 minutes after the spinal block except one patient in the Group BM-1. The one patient in the Group BM-2 showed sensory block level of L1 at 15 minutes after the spinal block, but the sensory block level reached $\mathrm{T} 10$ at 40-42 minutes after the spinal anesthesia. All of the patients in three groups had almost complete motor block ( 1 or 2 by 6-point modified Bromage scale) at 5 minutes after spinal anesthesia (Table 2). The systolic blood pressure, heart rate during the operation were not different among the groups (Fig. 1).

The duration of sensory block to T10 level after spinal anesthesia in the Group BM-2 were significantly longer than

Table 2. Anesthesia Data

\begin{tabular}{|c|c|c|c|}
\hline Variables & $\begin{array}{l}\text { Group B } \\
(\mathrm{n}=20)\end{array}$ & $\begin{array}{l}\text { Group BM-1 } \\
\quad(\mathrm{n}=21)\end{array}$ & $\begin{array}{l}\text { Group BM-2 } \\
(\mathrm{n}=19)\end{array}$ \\
\hline \multicolumn{4}{|l|}{$\begin{array}{l}\text { Sensory block } \\
\text { after S/A (minute) }\end{array}$} \\
\hline 5 & T11 (L2-T5) & T11 (L2-T6) T & T11 (L2-T6) \\
\hline 10 & T10 (L1-T4) & $\mathrm{T} 10(\mathrm{~L} 1-\mathrm{T} 5) \mathrm{T}$ & T10 (L2-T4) \\
\hline 15 & T9 (T12-T3) & T9 (T12-T4) & T9 (L1-T6) \\
\hline $\begin{array}{l}\text { Motor block grade } \\
\text { after S/A (minute) }\end{array}$ & $1 / 2 / 3 / 4 / 5$ & $1 / 2 / 3 / 4 / 5$ & $1 / 2 / 3 / 4 / 5$ \\
\hline 5 & $16 / 4 / 0 / 0 / 0$ & $16 / 5 / 0 / 0 / 0$ & $16 / 3 / 0 / 0 / 0$ \\
\hline 10 & $20 / 0 / 0 / 0 / 0$ & $21 / 0 / 0 / 0 / 0$ & $19 / 0 / 0 / 0 / 0$ \\
\hline 15 & $20 / 0 / 0 / 0 / 0$ & $21 / 0 / 0 / 0 / 0$ & $19 / 0 / 0 / 0 / 0$ \\
\hline $\begin{array}{l}\text { Duration of sensory } \\
\text { block to T10 } \\
\text { (minute) }\end{array}$ & $117 \pm 29.1$ & $127 \pm 41.11$ & $169.2 \pm 60.6^{*^{+}}$ \\
\hline
\end{tabular}

Values are in median (range), number of patients, mean \pm SD. Group B: $0.5 \%$ hyperbaric bupivacaine $+0.4 \mathrm{ml}$ of $0.9 \%$ saline, Group BM-1: bupivacaine + midazolam $1 \mathrm{mg}$ in $0.2 \mathrm{ml}+0.2 \mathrm{ml}$ of $0.9 \%$ saline, Group BM-2: bupivacaine + midazolam $2 \mathrm{mg}$ in $0.4 \mathrm{ml}$. ${ }^{*} \mathrm{P}$ $<0.05$ compared with the Group $\mathrm{B},{ }^{\dagger} \mathrm{P}<0.05$ compared with the Group BM-1. 
that of the Group B and the Group BM-1, respectively (Group B; $117 \pm 29.1$ minutes, Group BM-1; $127 \pm 41.1$ minutes, Group BM-2; $169.2 \pm 60.6$ minutes, $\mathrm{P}=0.009$, Table 2).

The OAA/S scale of Group BM-2 were significantly higher than that of the Group B and the Group BM-1 during the

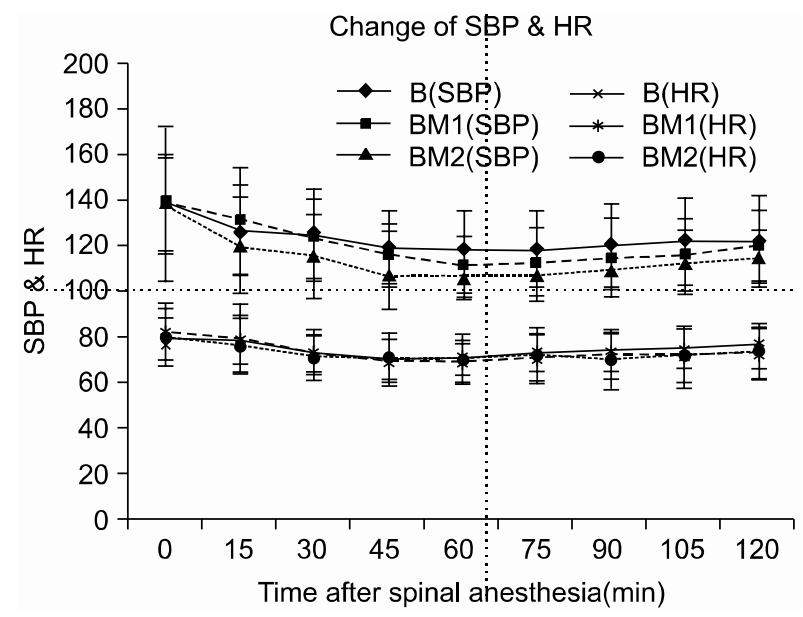

Fig. 1. Change of systolic blood pressure and heart rate. Bars indicate standard deviation. The horizontal axis represents the time from the spinal anesthesia. The vertical axis represents the systolic blood pressure and heart rate. B: Group B, $0.5 \%$ hyperbaric bupivacaine + $0.4 \mathrm{ml}$ of $0.9 \%$ saline, BM1: Group BM-1, bupivacaine + midazolam $1 \mathrm{mg}$ in $0.2 \mathrm{ml}+0.2 \mathrm{ml}$ of $0.9 \%$ saline, BM2: Group BM-2, bupivacaine + midazolam $2 \mathrm{mg}$ in $0.4 \mathrm{ml}$. SBP: systolic blood pressure, HR: heart rate. There were no significant differences among the three groups. operation $(P=0.005$, Fig. 2). BIS, however, did not show significant difference among the three groups (Fig. 3). The incidence of partial amnesia were significantly higher in the Group BM-2 than the other two groups (partial amnesia [yes/no], 0/20, 2/19, 16/3 in the Group B, Group BM-1, Group $\mathrm{BM}-2$, respectively. $\mathrm{P}=0.01$ ). There were statistically significant difference in the incidence of partial amnesia between the Group B and Group BM-1 $(\mathrm{P}=0.02)$. Those patients who experienced partial amnesia described that they

Table 3. Side Effects

\begin{tabular}{|c|c|c|c|}
\hline Variables & $\begin{array}{l}\text { Group B } \\
(\mathrm{n}=20)\end{array}$ & $\begin{array}{l}\text { Group BM-1 } \\
(\mathrm{n}=21)\end{array}$ & $\begin{array}{l}\text { Group BM-2 } \\
(\mathrm{n}=19)\end{array}$ \\
\hline Hypotension (OR/PAR) & $4 / 0$ & $5 / 0$ & $4 / 0$ \\
\hline Bradycardia (OR/PAR) & $0 / 0$ & $1 / 0$ & $0 / 0$ \\
\hline Nausea/vomiting (PAR) & $1 / 0$ & $1 / 0$ & $1 / 0$ \\
\hline Oversedation (OR/PAR) & $0 / 0$ & $0 / 0$ & $1 / 0$ \\
\hline Dizziness (PAR) & 1 & 0 & 0 \\
\hline $\begin{array}{l}\text { Airway obstruction } \\
\text { (OR/PAR) }\end{array}$ & $0 / 0$ & $0 / 0$ & $0 / 0$ \\
\hline $\mathrm{SpO}_{2}<95 \%(\mathrm{OR} / \mathrm{PAR})$ & $0 / 0$ & $0 / 0$ & $0 / 0$ \\
\hline Satisfaction score $(0-10)$ & $0(7-10)$ & $10(4-10)$ & $(5-10)$ \\
\hline
\end{tabular}

Values are in number of patients, median (range). Group B: $0.5 \%$ hyperbaric bupivacaine $+0.4 \mathrm{ml}$ of $0.9 \%$ saline, Group BM-1: bupivacaine + midazolam $1 \mathrm{mg}$ in $0.2 \mathrm{ml}+0.2 \mathrm{ml}$ of $0.9 \%$ saline, Group BM-2: bupivacaine + midazolam $2 \mathrm{mg}$ in $0.4 \mathrm{ml}$. OR/PAR: operation room/postanesthetic recovery room.

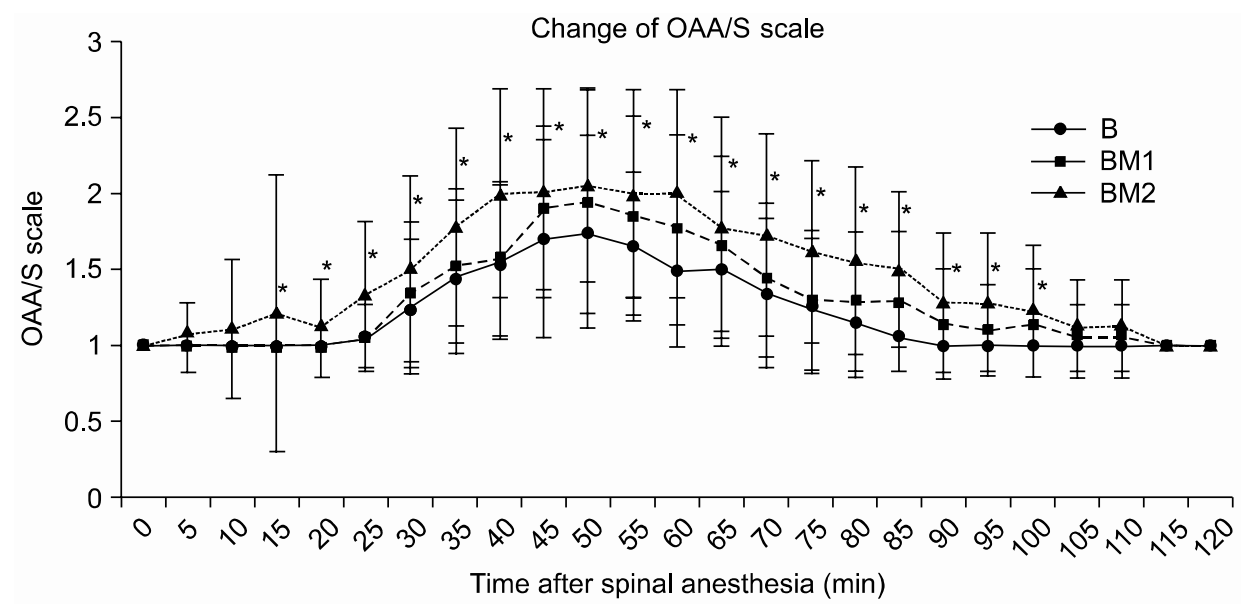

Fig. 2. Change of observer's assessment of alertness/sedation $(\mathrm{OAA} / \mathrm{S})$ scale. Bars indicate standard deviation. The horizontal axis represents the time from the spinal anesthesia. The vertical axis represents the OAA/S scale. B: Group B, $0.5 \%$ hyperbaric bupivacaine $+0.4 \mathrm{ml}$ of $0.9 \%$ saline. BM1: Group BM-1, bupivacaine + midazolam $1 \mathrm{mg}$ in $0.2 \mathrm{ml}+0.2 \mathrm{ml}$ of $0.9 \%$ saline, BM2: Group BM-2, bupivacaine + midazolam 2 $\mathrm{mg}$ in $0.4 \mathrm{ml}$. There were significant differences between Group BM-2 and the Group B. ${ }^{*} \mathrm{P}<0.05$ compared with the Group B. 


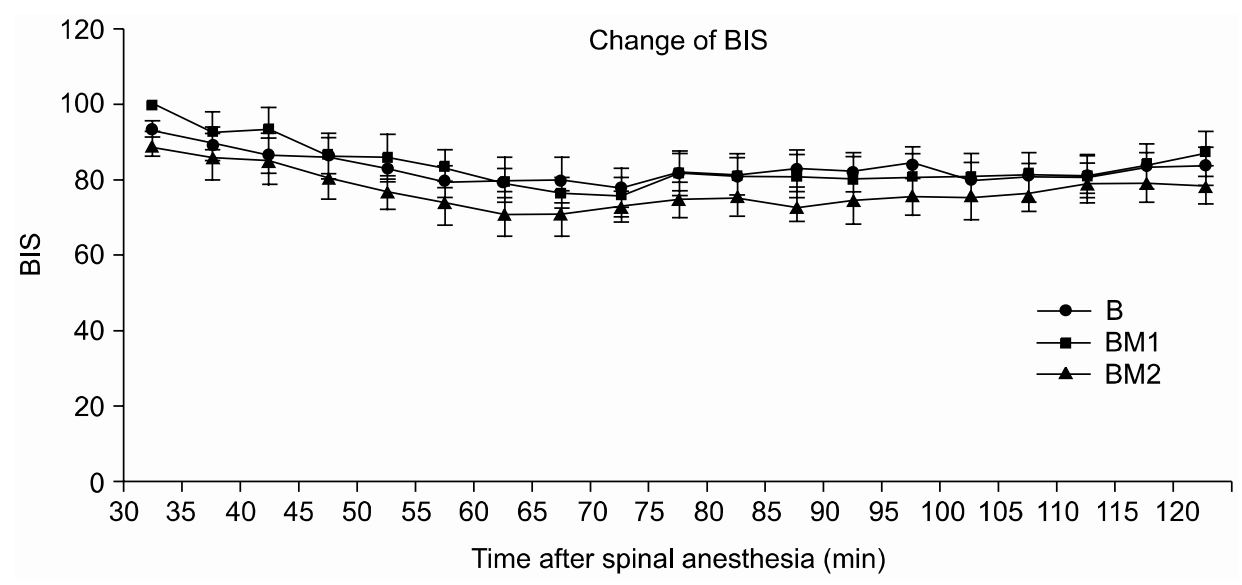

Fig. 3. Change of bispectral index (BIS). Bars indicate standard deviation. The horizontal axis represents the time from the spinal anesthesia. The vertical axis represents the BIS. B: Group B, $0.5 \%$ hyperbaric bupivacaine $+0.4 \mathrm{ml}$ of $0.9 \%$ saline. BM1: Group BM- 1 , bupivacaine + midazolam $1 \mathrm{mg}$ in $0.2 \mathrm{ml}+0.2 \mathrm{ml}$ of $0.9 \%$ saline, BM2: Group BM-2, bupivacaine + midazolam $2 \mathrm{mg}$ in $0.4 \mathrm{ml}$. There were no significant differences among the three groups.

slept for a brief period of time after the spinal block. There were no patients who had complete amnesia about the processes in operating room.

Two patients in Group BM-2, showed marked decrease of SBP due to high spinal anesthesia. In one patient of two mentioned patients, SBP started to decrease at 20 minutes after the spinal block and decreased maximally to $57 \%$ of baseline value $(89-74 \mathrm{mmHg}$ ) and returned slowly to baseline range at 50 minutes after the start of spinal block by the injection of total $20 \mathrm{mg}$ of ephedrine. The maximal sensory block level of the patient was T6. The other patient became unconscious and hypotensive (60-70\% of baseline value) from 15 minutes after the spinal block and was switched to general anesthesia with laryngeal mask airway.

Two patients in the Group BM-1 complained mild to moderate pain in recovery room and fentanyl (50 ug) was administered to each patient. One of two patients started IV-PCA with hydromorphone because the pain did not decrease less than mild degree. The fentanyl or hydromorphone did not affect the sedation or amnesia of two patients.

\section{DISCUSSION}

In our study, the mean duration of spinal block to T10 level in the Group BM-2 were significantly prolonged than that of the other 2 groups (52.2, 42.2 minutes longer than that of the Group B and the Group BM-1, respectively). These results suggest that small dose of IT midazolam would be a beneficial adjunct to spinal block with bupivacaine for lower extremity surgery with tourniquet.

Bharti et al. ${ }^{9)}$ reported that intrathecal addition of $1 \mathrm{mg}$ of midazolam to bupivacaine significantly increased the duration of sensory and motor blockade (to S2 dermatome). Yegin et al. $^{10)}$ also demonstrated postoperative analgesic effect of $2 \mathrm{mg}$ of IT midazolam was longer than that of the control group after perianal surgery. Most of the similar studies ${ }^{8-10)}$ assessed the duration of sensory block by the time from start of the block to the regression to the lower lumbar or perianal area. However, it is not important information for the lower extremity surgery with a tourniquet. Therefore we assessed the duration of sensory blockade to T10 dermatome. In the present study, IT midazolam of $2 \mathrm{mg}$ added to bupivacaine significantly prolonged the duration of sensory blockade to T10 dermatome. These results suggest that addition of $2 \mathrm{mg}$ IT midazolam to bupivacaine could be used for orthopedic surgery with a long operation time such as a revision of total hip or knee replacement or a complicated operation on the hip or femur.

Midazolam, when applied intrathecally, might gain access to analgesic systems mediated by GABA. Kohno et al. ${ }^{18)}$ reported that the analgesic effect of IT midazolam is induced by an action on GABAergic transmission in substantia gelatinosa neurons of adult rat spinal cord slices. In other study, ${ }^{19)}$ they reported that the midazolam reduced excitatory synaptic transmission by acting on the gamma-aminobutyric acid type A/benzodiazepine receptor in interneurons, leading to a 
decrease in the excitability of spinal dorsal horn neurons.

The clinical use of intrathecal midazolam in patients needs precautions because there have been several studies with different results about the possible neurotoxicity of intrathecal midazolam in animal. Few animal studies have found histopathological evidence of neurotoxicity in rats and rabbits after the use of intrathecal midazolam. ${ }^{20-22)}$ Various other histopathological studies in animals ${ }^{23,24}$ have shown that IT midazolam does not cause any morphological changes in the spinal cord which are suggestive of midazolam-induced neurotoxicity. Borg and Krijnen ${ }^{25)}$ also reported that the continuous intrathecal administration of midazolam and clonidine produced almost immediate and nearly complete pain relief without tolerance or side effects. We found no neurologic complications during 2 week follow up after spinal anesthesia, either.

According to our clinical experience before the start of this study, the sedative effect of $2 \mathrm{mg}$ of IT midazolam was thought to be increased slowly after the spinal block for the some period of time during operation. Actually the median OAA/S scale increased smoothly to OAA/S 2 to 3 until 60 minutes after spinal block and then decreased. The onset of sedative effect of IT midazolam seemed to be slower than intravenous midazolam. The mechanism of sedative effect of IT midazolam was not defined but the cephalad spread in cerebrospinal fluid or systemic absorption may contribute. The sedative effect of Group BM-2 might not affect the pain perception because the most of patients showed less than 3 of OAA/S scale. The intraoperative sedative effects of IT midazolam are controversial. Yegin et al. ${ }^{10)}$ reported that the sedative scales were significantly higher in group received bupivacaine plus $2 \mathrm{mg}$ of midazolam, compared to bupivacaine only group. However, Bharti et al. ${ }^{9)}$ reported that the sedative scores were comparable in both groups. In addition, there are very little objective data on the sedative effect of IT midazolam. Our study is the first attempt that compared the sedative effect of IT midazolam using an objective method, BIS. There were statistically significant differences among the groups in OAA/S scale but the BIS, the objective assessment of the sedative effects of the IT midazolam, did not show a significant difference among the groups in our study. Further evaluations of the sedative effects of the IT midazolam with objective methods should be performed because the results between objective assessment (BIS) and the subjective method (OAA/S scale) were not consistent, and this is the limitation of our study.

Unfortunately, given the sample size based on the duration of sensory block, it is not possible to make conclusions that there were no differences in adverse effects and hemodynamic variables among the three groups.

The injection duration was restricted strictly to 2 minutes to avoid excessive cephalad spread of spinal block. The total volume of injectate was $2.6 \mathrm{ml}$ in all patients and it would possibly large amount in elderly patients in our study. Actually $10.5 \%$ of patients (2/19) in BM-2 group had life threatening complications such as hypotension associated with high spinal blocks or unconsciousness. Therefore addition of $2 \mathrm{mg}$ of IT midazolam to bupivacaine requires more rigorous attention especially in old and vulnerable patients. More than $2 \mathrm{mg}$ of IT midazolam has not been evaluated for analgesic or sedative effect until now. Further dose-response studies are required to find an optimal dose without side effects.

In conclusion, the present investigation demonstrated that 2 $\mathrm{mg}$ of IT midazolam added to bupivacaine prolonged the duration of sensory block to T10 than bupivacaine alone or 1 $\mathrm{mg}$ of IT midazolam. IT midazolam of $2 \mathrm{mg}$ in elderly patients needs special attention to avoid possible life threatening hypotension or unconsciousness.

\section{ACKNOWLEDGEMENT}

The authors appreciated the statistical advice from professor Byoung Ju Park, Seo Kyoung Han of the Medical Research Collaborating Center at the University Hospital and the University College of Medicine.

\section{REFERENCES}

1. Chaney MA: Side effects of intrathecal and epidural opioids. Can J Anaesth 1995; 42: 891-903.

2. Kanazi GE, Aouad MT, Jabbour-Khoury SI, Al Jazzar MD, Alameddine MM, Al-Yaman R, et al: Effect of low-dose dexmedetomidine or clonidine on the characteristics of bupivacaine spinal block. Acta Anaesthesiol Scand 2006; 50: 222-7.

3. Niv D, Whitwam JG, Loh L: Depression of nociceptive sympathetic reflexes by the intrathecal administration of midazolam. Br J Anaesth 1983; 55: 541-7.

4. Goodchild CS, Serrao JM: Intrathecal midazolam in the rat: evidence for spinally-mediated analgesia. Br J Anaesth 1987; 59: 1563-70.

5. Crawford ME, Jensen FM, Toftdahl DB, Madsen JB: Direct spinal effect of intrathecal and extradural midazolam on visceral noxious 
stimulation in rabbits. Br J Anaesth 1993; 70: 642-6.

6. Goodchild CS, Noble J: The effects of intrathecal midazolam on sympathetic nervous system reflexes in man--a pilot study. Br J Clin Pharmacol 1987; 23: 279-85.

7. Serrao JM, Marks RL, Morley SJ, Goodchild CS: Intrathecal midazolam for the treatment of chronic mechanical low back pain: a controlled comparison with epidural steroid in a pilot study. Pain 1992; 48: 5-12.

8. Han MA, Kim MJ: The effects of intrathecal midazolam added to bupivacaine on duration of sensory block and BIS sedation score. Korean J Anesthesiol 2006; 50: 408-12.

9. Bharti N, Madan R, Mohanty PR, Kaul HL: Intrathecal midazolam added to bupivacaine improves the duration and quality of spinal anaesthesia. Acta Anaesthesiol Scand 2003; 47: 1101-5.

10. Yegin A, Sanli S, Dosemeci L, Kayacan N, Akbas M, Karsli B: The analgesic and sedative effects of intrathecal midazolam in perianal surgery. Eur J Anaesthesiol 2004; 21: 658-62.

11. Lee YM, Kim MH, Choi YJ, Choi SJ, Kim JA: The effect of intrathecal midazolam on bupivacaine induced spinal anesthesia after hemorrhoidectomy. Korean J Anesthesiol 2000; 38: 404-8.

12. Sen A, Rudra A, Sarkar SK, Biswas B: Intrathecal midazolam for postoperative pain relief in caesarean section delivery. J Indian Med Assoc 2001; 99: 683-4, 686.

13. Lee JM, Ju YH, Lee SK, Cho HW, Park JH, Moon HS: The effects of intrathecal midazolam added to bupivacaine spinal anesthesia. Korean J Anesthesiol 2006; 50: 66-71.

14. Wu YW, Shiau JM, Hong CC, Hung CP, Lu HF, Tseng CC: Intrathecal midazolam combined with low-dose bupivacaine improves postoperative recovery in diabetic mellitus patients undergoing foot debridement. Acta Anaesthesiol Taiwan 2005; 43: 129-34.

15. Chernik DA, Gillings D, Laine H, Hendler J, Silver JM, Davidson $\mathrm{AB}$, et al: Validity and reliability of the observer's assessment of alertness/sedation scale: study with intravenous midazolam. J Clin
Psychopharmacol 1990; 10: 244-51.

16. De Kock M, Gautier P, Fanard L, Hody JL, Lavand'homme P: Intrathecal ropivacaine and clonidine for ambulatory knee arthroscopy: a dose-response study. Anesthesiology 2001; 94: 574-8.

17. Ready L: Acute perioperative pain. In: Anesthesia. 5th ed. Edited by Miller R: Philadelphia, Churchill Livingstone. 2002, pp 2323-50.

18. Kohno T, Wakai A, Ataka T, Ikoma M, Yamakura T, Baba H: Actions of midazolam on excitatory transmission in dorsal horn neurons of adult rat spinal cord. Anesthesiology 2006; 104: $338-43$.

19. Kohno T, Kumamoto E, Baba H, Ataka T, Okamoto M, Shimoji $\mathrm{K}$, et al: Actions of midazolam on GABAergic transmission in substantia gelatinosa neurons of adult rat spinal cord slices. Anesthesiology 2000; 92: 507-15.

20. Malinovsky JM, Cozian A, Lepage JY, Mussini JM, Pinaud M, Souron R: Ketamine and midazolam neurotoxicity in the rabbit. Anesthesiology 1991; 75: 91-7.

21. Svensson BA, Welin M, Gordh $\mathrm{T} \mathrm{Jr}$, Westman J: Chronic subarachnoid midazolam (Dormicum) in the rat. Morphologic evidence of spinal cord neurotoxicity. Reg Anesth 1995; 20: 426-34.

22. Erdine S, Yucel A, Ozyalcin S, Ozyuvaci E, Talu GK, Ahiskali B, et al: Neurotoxicity of midazolam in the rabbit. Pain 1999; 80 : 419-23.

23. Schoeffler P, Auroy P, Bazin JE, Taxi J, Woda A: Subarachnoid midazolam: histologic study in rats and report of its effect on chronic pain in humans. Reg Anesth 1991; 16: 329-32.

24. Nishiyama $T$, Matsukawa $T$, Hanaoka $K$ : Acute phase histopathological study of spinally administered midazolam in cats. Anesth Analg 1999; 89: 717-20.

25. Borg PA, Krijnen HJ: Long-term intrathecal administration of midazolam and clonidine. Clin J Pain 1996; 12: 63-8. 